\title{
LAS CUEVAS DE LEVANTE (BENALUP, CÁDIZ): UN YACIMIENTO AL AIRE LIBRE DEL PALEOLÍTICO SUPERIOR EN ANDALUCÍA SUROCCIDENTAL
}

\author{
CUEVAS DE LEVANTE (CÁDIZ, SPAIN): \\ AN UPPER PALAEOLITHIC OPEN AIR \\ SITE IN SOUTHWESTERN ANDALUSIA
}

\author{
SERGIO RIPOLL LÓPEZ (*) \\ MARTÍ MAS CORNELLÀ $(*)$ \\ JESÚS F. JORDÁ PARDO $(* *)$
}

\begin{abstract}
RESUMEN
En este artículo damos a conocer los resultados de la excavación arqueológica realizada en el yacimiento al aire libre situado delante de las Cuevas de Levante (Cádiz, España) durante 1991, así como la interpretación geoarqueológica del mismo. La industria lítica recuperada nos permite encuadrar esta estación en el Solutrense.
\end{abstract}

\begin{abstract}
In this article we give the results of the archaeological excavation carried out on the open-air site located in front of the Cuevas de Levante (Cádiz, Spain) in October 1991, and the geoarchaeological interpretation of the site. The lithic industry recovered allows us to place this site in the Solutrean.
\end{abstract}

Palabras clave: Yacimiento al aire libre. Paleolítico Superior. Solutrense. Pleistoceno Superior. Arqueología de urgencia. Geoarqueología.

(*) Departamento de Prehistoria e Historia Antigua. Facultad de Geografía e Historia. Universidad Nacional de Educación a Distancia. Senda del Rey, s/n. Ciudad Universitaria. $28040 \mathrm{Ma}-$ drid.

(**) Laboratorio de Estudios Paleolíticos. Departamento de Prehistoria e Historia Antigua. Facultad de Geografía e Historia. Universidad Nacional de Educación a Distancia. Senda del Rey, s/ n. Ciudad Universitaria. 28040 Madrid.

El artículo fue remitido en su versión final el 12-V-98.
Key words: Open-air site. Upper Palaeolithic. Solutrean. Upper Pleistocene. Rescue archaeology. Geoarchaeology.

\section{INTRODUCCIÓN}

Dentro del proyecto de investigación "Las manifestaciones rupestres prehistóricas de la zona gaditana" (1) (Mas Cornellà, 1993; Mas Cornellà et alii, 1996) llevamos a cabo en 1990 una prospección arqueológica superficial en las Cuevas de Levante (Láms. I y II) y Cubeta de la Paja en cuyo informe (Mas Cornellà y Sanchidrián Torti, 1990) señalábamos que nos encontrábamos ante dos yacimientos de una gran singularidad e interés inesperado, que ofrecían un caudal de información elevado y cuya distribución espacial se veía constreñida a áreas muy reducidas. Realizamos esta prospección arqueológica superficial motivados por el interés que suscitaba el material que nos cedió en 1987 Ramón Viñas Vallverdú para su estudio, una colección de piezas líticas procedentes de un lugar situado a menos de doscientos metros de la Cueva del Tajo de las Figuras (Cubeta de la Paja), localizada en superficie el año 1980, a la que ya habíamos hecho referencia en anteriores trabajos (Mas Cornellà, 1986-87: 252, 1988: 300). Ya H. Breuil y M.

(1) Estas actividades arqueológicas fueron autorizadas y subvencionadas por la Dirección General de Bienes Culturales de la Consejería de Cultura de la Junta de Andalucía. 


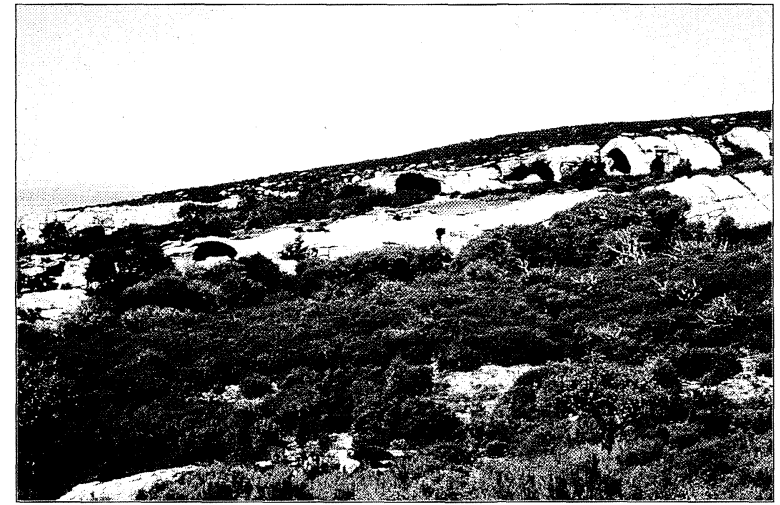

Lám. I. Cuevas de Levante.

C. Burkitt se habían referido a la riqueza arqueológica de este lugar cuando describían la figura pintada de la Cueva de la Paja: "Close by and a little higher up [de la Cueva de la Paja] is another grotto containing some more or less recent drawings in black. On the slope between the two cavities numerous pieces of flint may be found" (Breuil y Burkitt, 1929: 38).

Posteriormente, durante la campaña de trabajo de campo dedicada, en 1989, a la reproducción y estudio directo del arte rupestre en Sierra Momia y Valle del Río de las Cañas o Palmones, Andrés Mañé Ordóñez, vigilante del Conjunto rupestre del Tajo de las Figuras, nos comunicó la existencia de otro lote lítico hallado por él en superficie durante sus años de guarda, el cual puso a nuestra disposición. A partir de estas informaciones pasamos a localizar dos enclaves en los que abundaba el material lítico, que correspondían a los topónimos de Cuevas de Levante (Lám. I y II) y Cubeta de la Paja (Conjunto rupestre del Tajo de las Figuras), los cuales visitamos en septiembre de 1989, pudiendo constatar su riqueza.

A la vista de todo ello, solicitamos a la Dirección General de Bienes Culturales de la Consejería de Cultura y Medio Ambiente de la Junta de Andalucía permiso para la realización de una prospección arqueológica superficial limitada a estos dos sitios, con la finalidad de aproximarnos al hasta ahora prácticamente desconocido contexto arqueológico de las pinturas rupestres ejecutadas en los abrigos de Sierra Momia. Aunque la relación entre los yacimientos a estudiar, considerábamos, y los conjuntos artísticos no tiene porqué ser evidente, creíamos interesante, para poder aproximarnos a su significado, conocer de la forma más detallada posible el entorno en que se encuentran inmersas estas esta-

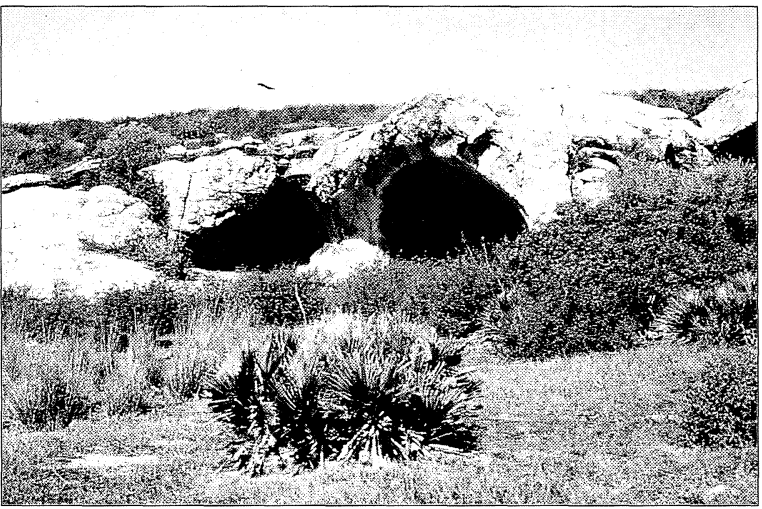

Lám. II. Cuevas de Levante II (o 1) y III (o 2).

ciones pictóricas. Esta actuación fue concedida y la llevamos a cabo en 1990 (Mas Cornellà y Sanchidrian Torti, 1990), obteniendo en estos dos espacios extremadamente reducidos, como se ha indicado, y a partir de metodologías específicas diseñadas en función de las características de los yacimientos, mil seiscientas sesenta y una (Cuevas de Levante) (Lám. III y IV) y setecientas treinta y seis (Cubeta de la Paja) piezas líticas.

En el informe redactado a propósito de la prospección arqueológica superficial, señalábamos que el estado de conservación de ambos yacimientos era preocupante. Los materiales esparcidos a flor de tierra eran susceptibles de recogidas incontroladas, si bien los agentes naturales serían los factores principales de su destrucción. Los fenómenos atmosféricos estaban acabando con el sucinto paquete arqueológico, que en la Cubeta de la Paja apenas alcanzaba los $10 \mathrm{~cm}$. de potencia máxima, desplazando y descontextualizando los objetos en el mejor de los casos, y haciéndolos desaparecer por medio de las escorrentías la mayoría de las veces. En las Cuevas de Levante (Lám. I, II, III y IV) ocurría algo similar, aunque aquí el problema se agudizaba por la posible mezcla de piezas de otras estaciones próximas. Urgía por tanto, llevar a cabo medidas y actuaciones especiales destinadas al aislamiento y protección de los sedimentos o, en su defecto, por causas de rentabilidad o dificultades técnicas, a la recuperación de estas importantes evidencias.

En consecuencia, y siguiendo estas consideraciones, creímos que sería conveniente llevar a cabo, a principios de octubre de 1991, una actuación de urgencia que iniciamos con el reconocimiento de las zonas especificadas, con el fin de diagnosticar el estado actual de la cuestión y plantear la interven- 


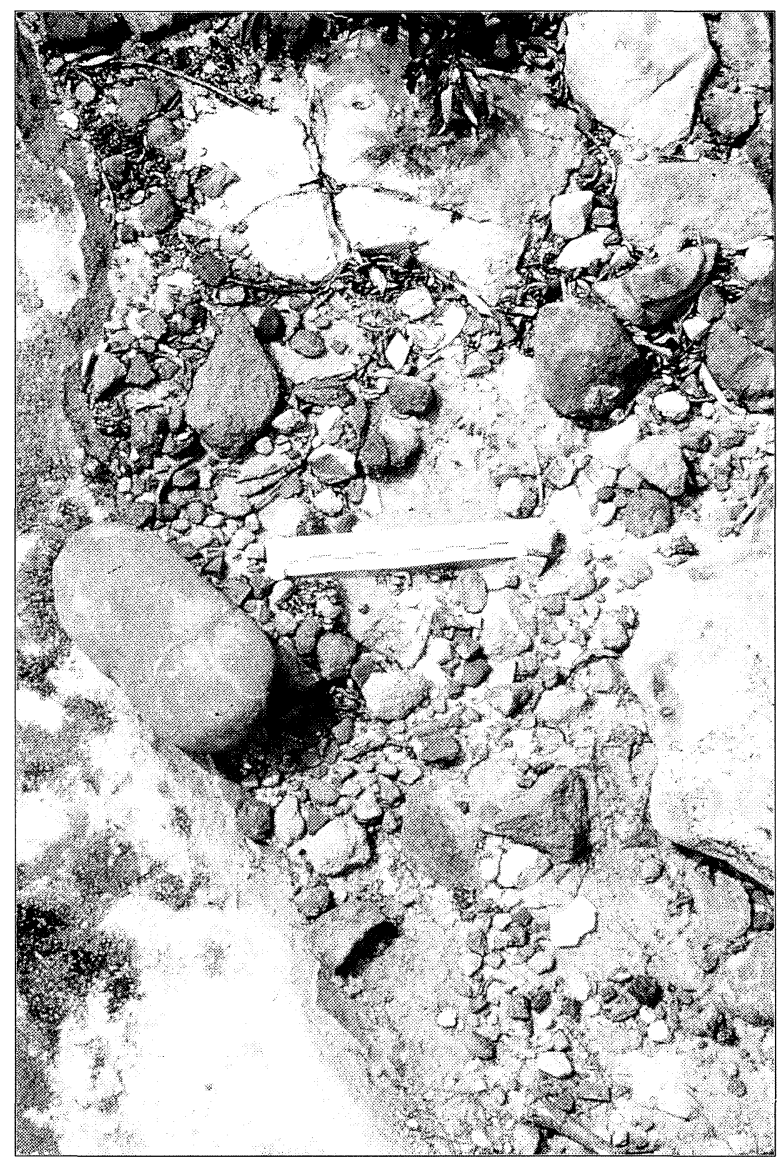

Lám. III. Detalle en el que se aprecia el aspecto que ofrecían los sedimentos y los restos líticos antes de su retirada durante la prospección de 1990.

ción más idónea en función de la problemática en torno a la conservación de estos lugares. Se decidió realizar una prospección con sondeos estratigráficos en ambos yacimientos para determinar su potencia estratigráfica y recuperar parte o la totalidad del paquete arqueológico de unos yacimientos, que como ya hemos indicado, creíamos que eran de reducidas dimensiones (2).

Los resultados obtenidos en el sondeo realizado en octubre de 1991 en las Cuevas de Levante los plasmamos en este trabajo. Nuestra intención era también realizar un sondeo estratigráfico en la $\mathrm{Cu}$ beta de la Paja, pero éste no dio ningún resultado en la zona prevista, al igual que cuando lo intentamos

(2) Esta actuación fue autorizada por la Dirección General de Bienes Culturales de la Consejería de Cultura y Medio Ambiente de la Junta de Andalucía a través de su Delegación Provincial en Cádiz (Ripoll López et alii, 1993). Agradecemos a Guadalupe Torra Colell y José Diego Flor Marchante su colaboración en las tareas de excavación.

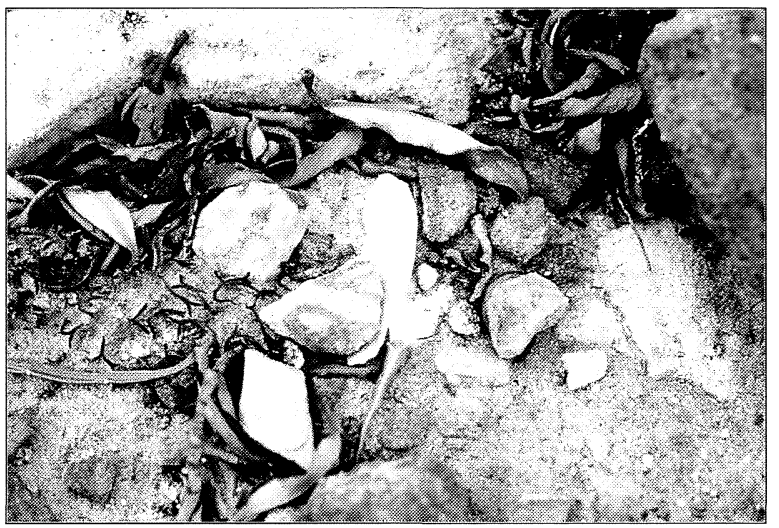

Lám. IV. Ampliación de una hojita de sílex completa, aprisionada por un pequeño canto de arenisca, que veíamos en la lámina III.

en otros lugares de este abrigo a la vista de los primeros resultados negativos.

\section{METODOLOGÍA}

En la excavación del sondeo llevada a cabo en las Cuevas de Levante (Láms. V y VI), el método de excavación utilizado, con algunas diferencias de adaptación, es el resultado de la aplicación del control estratigráfico y el registro tridimensional, propuesto por L. Méroc (1930), y el método desarrollado porA. Leroi-Gourhan (1952), donde el decapado de las diferentes superficies de los niveles, con el objeto de localizar posibles estructuras, constituye el objetivo esencial. No se trataba de contraponer los dos métodos, sino de conjugarlos armónicamente. El control estratigráfico y el registro tridimensional son necesarios para determinar y archivar los vestigios hallados en un decapado cuidadoso. Por esta razón nosotros hemos adoptado estos métodos a la particular idiosincrasia del yacimiento de las Cuevas de Levante, utilizando un triple control:

- Control vertical. En el que se trata de registrar la distribución vertical del material arqueológico, mediante el nivel óptico, siempre referido al punto "0" general para toda la excavación. El punto "0" de las Cuevas de Levante fue fijado en la pared derecha (Norte) del abrigo III a unos $30 \mathrm{~cm}$ de la roca madre actual. A partir del punto " 0 " se cuadriculó la zona de excavación.

- Control horizontal. Este tipo de control se realiza sobre los vestigios que aparecen durante la excavación en un plano horizontal. La cuadrícula 


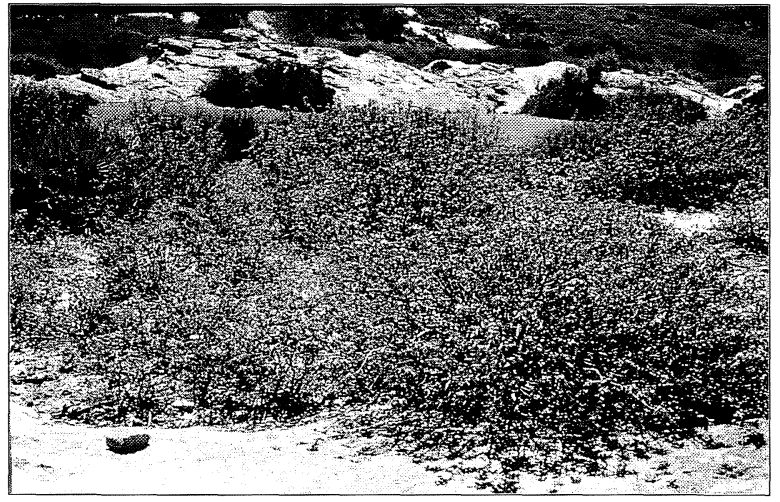

Lám.V. Aspecto de la zona (fotografía de 1989), frente a los abrigos II y III, en donde se realizó el sondeo estratigráfico.

marcada era de $1 \mathrm{~m}$. cuadrado y la denominamos según la cuadrícula establecida durante la campaña de prospección superficial. Dentro de esta cuadrícula de $1 \mathrm{~m}$. cuadrado se ha localizado cada uno de los hallazgos por medio del método de coordenadas cartesianas. Este criterio geométrico ha sido empleado para las piezas de mayor interés, piezas retocadas o para determinadas zonas en las que la localización exacta de dichos hallazgos pudiera tener un significado especial. Durante el transcurso de los trabajos de excavación se elaboró la correspondiente documentación de campo: diario, cuaderno de inventario, plantas de distribución espacial de restos, secciones y numerosas fotografías. El inventario de los materiales se formalizó en un cuaderno impreso ordenado por capas. En él se consignaron todas las circunstancias pertinentes de cada pieza: cuadrícula, sector, nivel, capa, coordenadas, orientación, buzamiento, número de orden, fecha del hallazgo, descripción, clasificación tipológica

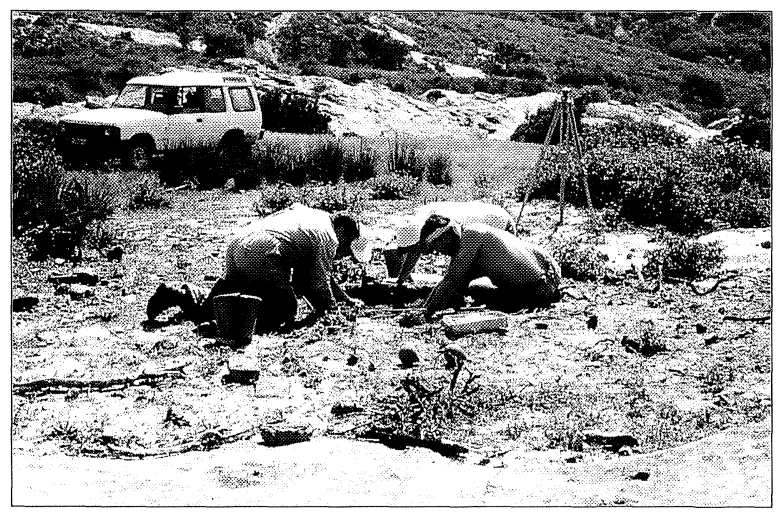

Lám. VI. Vista general de los trabajos de excavación. preliminar (cuando se trata de utensilios retocados) y observaciones complementarias. En estos mismos cuadernos se dibujaban las plantas de las distintas capas que se iban excavando. En ellas se situaban los restos más significativos, productos de talla y piezas retocadas, utilizando unos signos convencionales. En el caso de los útiles líticos se les daba además un número de orden que era con el que más tarde se siglarían.

- Control estratigráfico. Para llevarlo a cabo hemos utilizado los métodos descriptivos basados en los habituales criterios empíricos: diferencias de coloración y tono controlados por las tablas Munsell (1954), características de composición y textura del sedimento y otras peculiaridades (cementación, grado de humedad, acumulaciones de cenizas, etc).

También decidimos acometer la realización de un estudio geoarqueológico en las Cuevas de Levante, cuyos objetivos se centraron en tres aspectos fundamentales: determinación de la localización geológica y geomorfológica del yacimiento, identificación de los procesos que han configurado el yacimiento, e interpretación paleoambiental de la secuencia, siempre que los datos obtenidos lo permitieran. Para ello estructuramos el trabajo en tres fases: trabajo de campo, de laboratorio y de gabinete. El trabajo de campo lo llevamos a cabo en la campaña de 1991, durante la cual efectuamos un reconocimiento de la zona y del yacimiento, describiéndolo y muestreando la secuencia litoestratigráfica proporcionada por el sondeo arqueológico realizado. El trabajo de laboratorio fue realizado en los laboratorios generales del Instituto Tecnológico Geominero de España a partir de las muestras obtenidas y comprendió análisis texturales y mineralógicos. El trabajo de gabinete consistió en el estudio de las diferentes cartografías y fotografías aéreas, y en el tratamiento informático e interpretación de los datos obtenidos.

\section{MARCO GEOGRÁFICO Y GEOLÓGICO}

Los yacimientos conocidos bajo los nombres de Cuevas de Levante y Cubeta de la Paja se encuentran situados en el SO del macizo montañoso de Sierra Momia, que bordea por su lado NE la antigua Laguna de la Janda y se ubica en los actuales términos municipales deAlcalá de los Gazules, Benalup y Medina Sidonia, que ocupan la zona centro occidental de la provincia de Cádiz (Fig. 1). Su

T. P., 55, n. ${ }^{\circ} 2,1998$ 


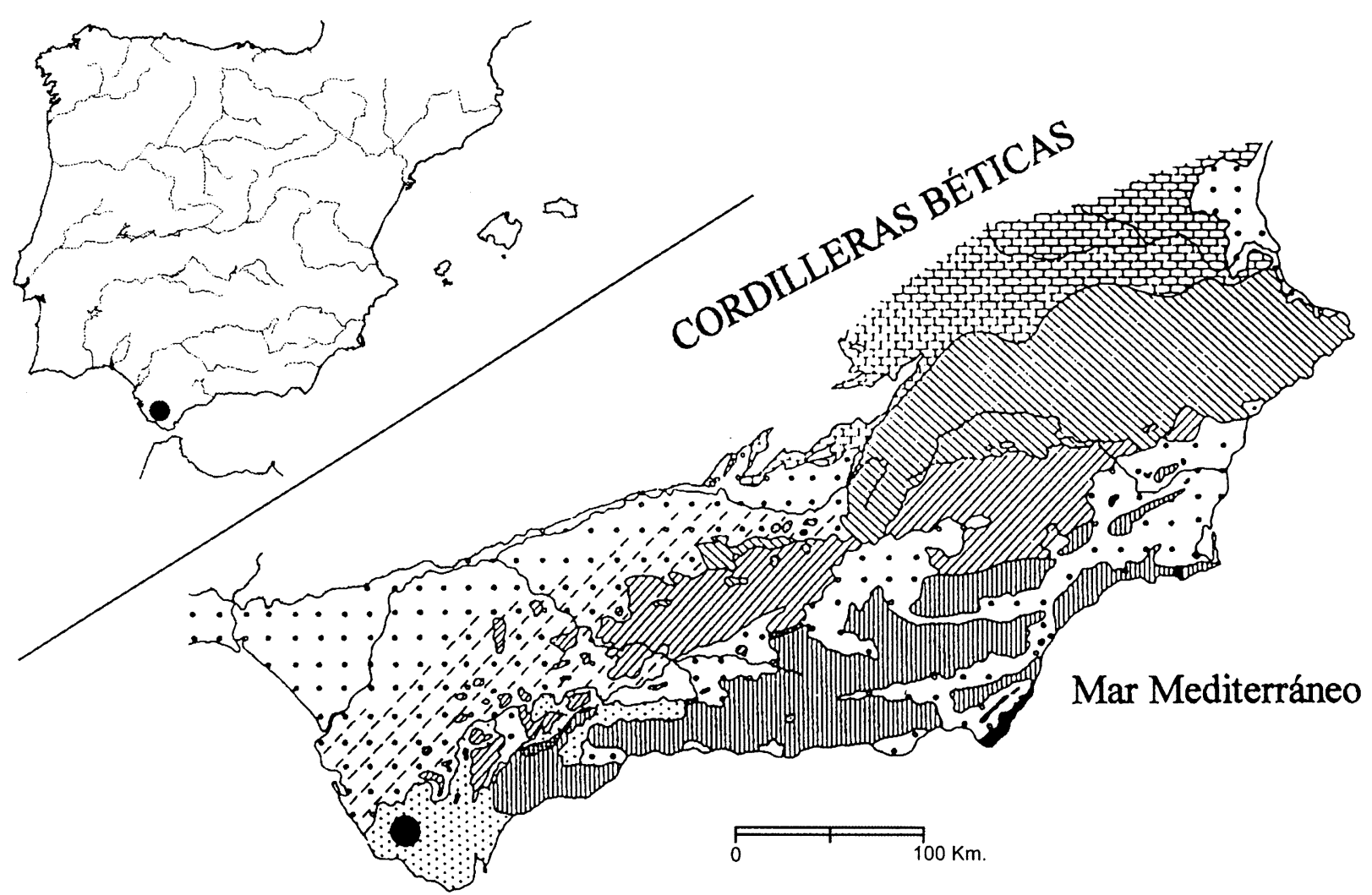

Fig. 1. Situación de las Cuevas de Levante en el contexto peninsular y en el contexto regional de las Cordilleras Béticas. La zona punteada de la provincia de Cádiz corresponde a las Unidades Alóctonas del Campo de Gibraltar (Fontoboté, 1983; Fontboté y Vera, 1983).

punto más elevado se localiza en la cumbre de Sierra Momia a 361 m. s.n.m.

Sierra Momia es un accidente geográfico situado en las Unidades Alóctonas del Campo de Gibraltar, dentro de las Cordilleras Béticas (Fig. 1). Estas Unidades forman un conjunto de mantos y escamas completamente desenraizados, constituidos principalmente por formaciones cretácicas y terciarias, en las cuales las de tipo flysh tienen una muy importante representación (Fontboté y Vera, 1983). Una de estas unidades que componen el Complejo del Campo de Gibraltar es la Unidad del Aljibe, situada entre el Senoniense (Cretácico Superior) y el Burdigaliense (Mioceno Medio), y es en una de las formaciones que culminan esta unidad, concretamente la Formación Areniscas del Aljibe, en donde se desarrollan las cavidades.

La Formación Areniscas del Aljibe (Gavala, 1916, 1929; Fontboté, 1983; ITGE, 1991) llega a alcanzar una potencia de $2.000-1.500 \mathrm{~m}$. y está formada predominantemente por areniscas de aspecto masivo, que son exclusivamente silíceas y tienen una coloración blanquecina o amarillenta en fractura fresca, que pasa a parda por meteorización, con finas intercalaciones de materiales pelíticos de color marrón claro. Son unas areniscas constituidas por granos de cuarzo, bien redondeados, de tamaño fino a grueso, a veces conglomeráticas, con apenas matriz, de carácter limoso y arenoso de grano muy fino y mala cementación, de tipo ferruginoso, no muy consistentes, por lo que la roca tiene una cierta friabilidad. Se presentan en bancos potentes que destacan en el relieve, con estructuras sedimentarias que indican claramente que estas areniscas se depositaron por corrientes de turbidez densas, en la parte media de abanicos submarinos profundos, observándose facies propias de lóbulos deposicionales y facies canalizadas. Las medidas de paleocorrientes permiten suponer una procedencia del S. Están afectadas por inestabilidades tectónicas, pudiéndose observar estructuras de deslizamiento, diques de arena, etc. Apenas contienen fósiles, por lo que su datación paleontológica es prácticamente imposible. No obstante el techo de los materia- 
les que descansan por debajo de las Areniscas del Aljibe tiene una edad Aquitaniense, mientras que las arcillas con intercalaciones de arenas que se sitúan a techo de las Areniscas delAljibe, tienen una edad Aquitaniense Superior - Burdigaliense. Por tanto las Areniscas delAljibe se depositan una vez iniciado el Aquitaniense, terminando su sedimentación en un momento no precisado, anterior al Aquitaniense Superior - Burdigaliense. Estas areniscas se pueden correlacionar claramente con el llamado Manto Numídico, al otro lado del Estrecho de Gibraltar (Fontboté, 1983).

Las Areniscas delAljibe están claramente tectonizadas por la Orogenia Alpina, encontrándose en la zona de Sierra Momia formando un sinclinal tumbado, cuyo eje tiene una dirección NO-SE, presentando un buzamiento invertido de $45^{\circ} \mathrm{SO}$ en la zona que nos ocupa. En las Sierras Sequilla y del Niño se observa un plegamiento con sistemas de sinclinales y anticlinales tumbados como el de Palomas, y además, esta formación se encuentra cortada por numerosas fallas normales de dirección EO y SO-NE, algunas de cierta extensión, produciendo desplazamientos verticales y horizontales en los materiales plegados. En los planos de estas fallas, claras zonas de debilidad, es frecuente el desarrollo de cavidades, como es el caso de la Cueva del Tajo de las Figuras. También se encuentra afectada esta formación por despegues que dan lugar a importantes cicatrices como la de la zona de Bacinete (Mas Cornellà et alii, 1994).

Geomorfológicamente, lasAreniscas delAljibe destacan en el relieve, dando lugar a varias alineaciones montañosas como las sierras Momia, Sequilla o del Niño, limitadas por áreas deprimidas, como la de la Laguna de la Janda. Estas sierras presentan la peculiaridad de contener numerosas cavidades o abrigos rocosos, de pequeño tamaño, originadas por corrosión y por erosión eólica, junto con superficies corroidas en extensión, dando lugar en conjunto a una morfología de tafonis en areniscas silíceas.

El conjunto de Cuevas de Levante (Fig. 2 y 3 ) se orienta hacia el E y SE, configurado por un total de seis abrigos rocosos, numerados de $\mathrm{S}$ a $\mathrm{N}$, siendo el II el único que posee representaciones pictóricas. Frente a éste y el contiguo (III) es dónde se localizan la mayor parte de los restos líticos (3) (Lám. II).

(3) Al referirnos a las manifestaciones rupestres los denominanos 1 y 2. El 1 es el conocido abrigo (Breuil y Burkitt, 1929: 37) que contiene veintiseis trazos verticales pintados en rojo alineados horizontalmente. En esta cavidad y la contigua (III o 2) se descubrieron en 1992, grabados paleolíticos (Cornellá, 1993).

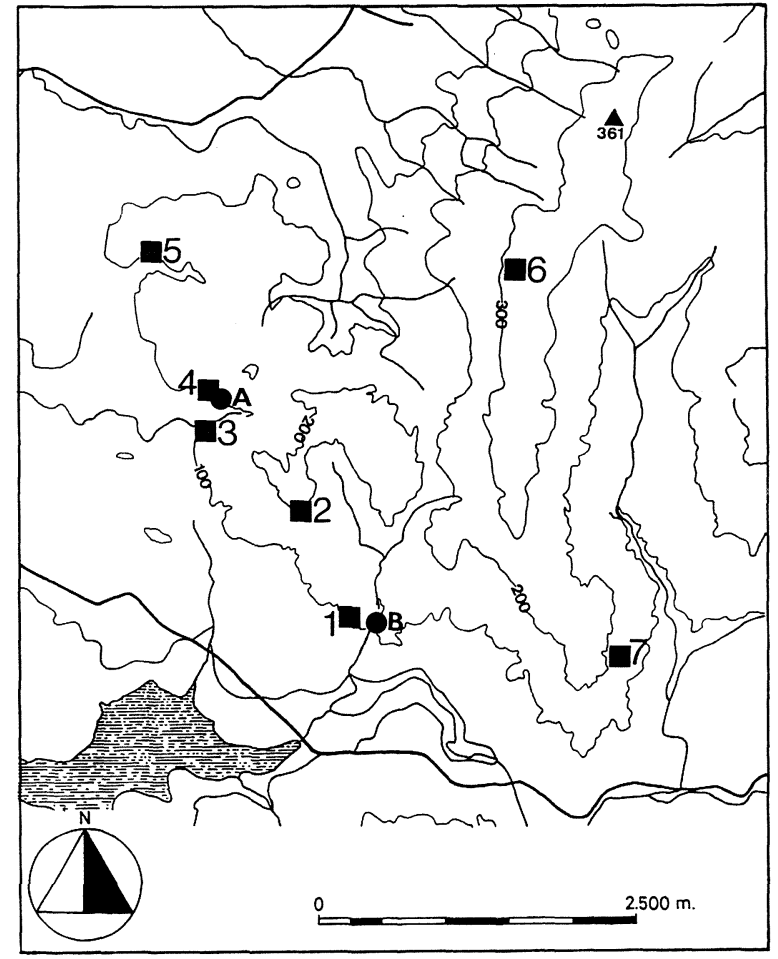

Fig. 2. Extremo SO de Sierra Momia. Se indican los dos yacimientos al aire libre localizados, Cuevas de Levante [A] y Cubeta de la Paja [B], y las cavidades conocidas con arte rupestre [1: Conjunto rupestre del Tajo de las Figuras; 2: Cueva de Luis Lázaro; 3: Cueva del Tajo Amarillo y Cueva Negra de las Pradillas; 4: Cuevas de Levante; 5 : Cuevas de los Ladrones o Pretinas; 6: Cueva del Tajo del Cabrito; y 7: Cueva del Cañuelo] (Modificado a partir de Mapa Militar de España. 1:50.000. Alcalá de los Gazules 13-46 (1.070), Servicio Geográfico del Ejército, Madrid, 1974, y Mapa Militar de España. 1:50.000. Tahivilla 13-47 (1.074), Servicio Geográfico del Ejército, Madrid, 1972). No deja de ser significativa la relación espacial de los dos yacimientos con las Cuevas de Levante, del Tajo de las Figuras y del Arco, los únicos cuatro abrigos con grabados rupestres paleolíticos (Ripoll López et alii, 1991; Mas Cornellà, 1993; Mas Cornellà et alii, 1995; Mas Cornellà y Ripoll López, 1996).

El resto de los abrigos, aún siendo de mayores dimensiones y de alguna forma mejor conformados para ofrecer una mejor habitabilidad, no posee ninguna evidencia, ya sea pictórica o industrial, debido probablemente a la erosión.

En cuanto a la estación de la Cubeta de la Paja, se trata de un abrigo hundido, situado en una cresta rocosa, muy cercana a la Cueva del Tajo de la Figuras. A primera vista, el conjunto ofrece un aspecto caótico, como consecuencia de fenómenos gravitacionales, así como erosivos y/o corrosivos. 


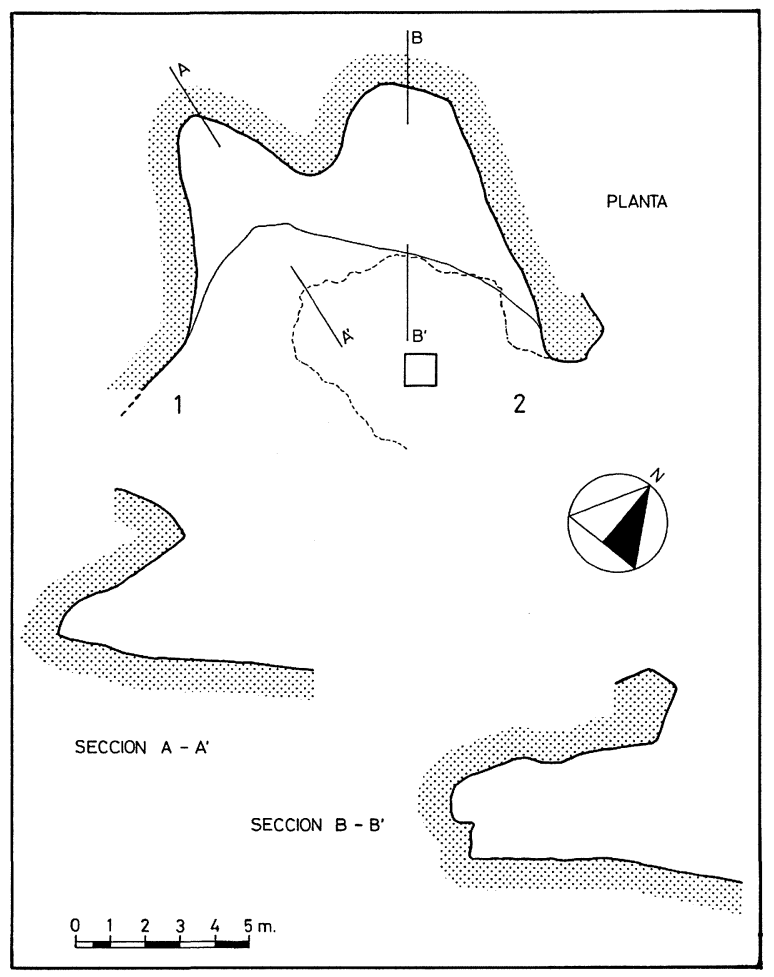

Fig. 3. Topografía de las Cuevas de Levante 1 (II) y 2 (III). El sondeo estratigráfico se realizó en el cuadro D-8 de la prospección de 1990 (Mas Cornellà y Sanchidrián Torti, 1990).

El sector oriental está cubierto por grandes bloques procedentes del desplome de la visera y el piso, levemente inclinado y horadado por numerosas cubetas. Los vestigios industriales se localizaron en una de estas oquedades en posición secundaria, arrastrados sin duda por escorrentía.

\section{ESTRATIGRAFÍA DEL YACIMIENTO}

\subsection{Litoestratigrafía}

Las Cuevas de Levante son una serie de cavidades con morfología de abrigo rocoso que se disponen de forma alineada (Fig. 2 y 3), desarrollándose sobre un paquete homogéneo de las Areniscas delAljibe, paquete que forma parte del flanco interno de un sinclinal tumbado, de tal forma que las capas de areniscas presentan un buzamiento invertido de $45^{\circ}$ hacia el SO, siendo su dirección $\mathrm{N} 128^{\circ} \mathrm{E}$. Estas cavidades ocupan la vertiente $\mathrm{N}$ del Arroyo de Gallardo, que desemboca en el Río Barbate por su margen izquierda. Este valle, cuando atraviesa las Areniscas del Aljibe está claramente controlado por la tectónica, dado que se ciñe a la traza de una falla de dirección EO que atraviesa dicha formación. Todas las cavidades están orientadas hacia el E-SE, de ahí su nombre. En total componen, como hemos indicado, un conjunto de seis pequeños abrigos rocosos, numerados de $\mathrm{S}$ a $\mathrm{N}$, de los cuales a nosotros nos interesa los denominados Levante II y III, delante de los cuales se realizó el sondeo arqueológico.

La secuencia litoestratigráfica que ofrecen los cortes de la cata de $1 \mathrm{~m}^{2}$ efectuada se componen de muro a techo de los siguientes niveles (Fig. 4):

- Sustrato rocoso constituido por las Areniscas del Aljibe.

- Nivel C.L.1: Arenas de color gris, con una potencia de 8 a $10 \mathrm{~cm}$. Existe un predominio absoluto de las arenas $(76,83 \%)$, que se encuentran bien redondeadas y son de naturaleza silícea.Aparecen limos en una proporción moderada $(17,2 \%)$, mientras que las arcillas $(3,52 \%)$ y la fracción gruesa $(2,45 \%)$ tienen una escasa presencia. Dentro de las arenas predominan las de grano fino y medio, que corresponden al tamaño de grano de la roca del sustrato. La fracción gruesa está formada exclusivamente por gravas de naturaleza areniscosa. Mineralógicamente, tanto las arenas como la fracción fina (inferior a 12 micras) están constituidas por cuarzo, apareciendo como mineral secundario el caolín y como accesorios y trazas micas y esmectita (mineral arcilloso). Contiene materia orgánica en pequeñas proporciones, que confiere al conjunto el tono grisáceo, y no se observa la presencia de carbonatos. Su geometría es tabular y su aspecto masivo y homogéneo. Corresponde al nivel arqueo-

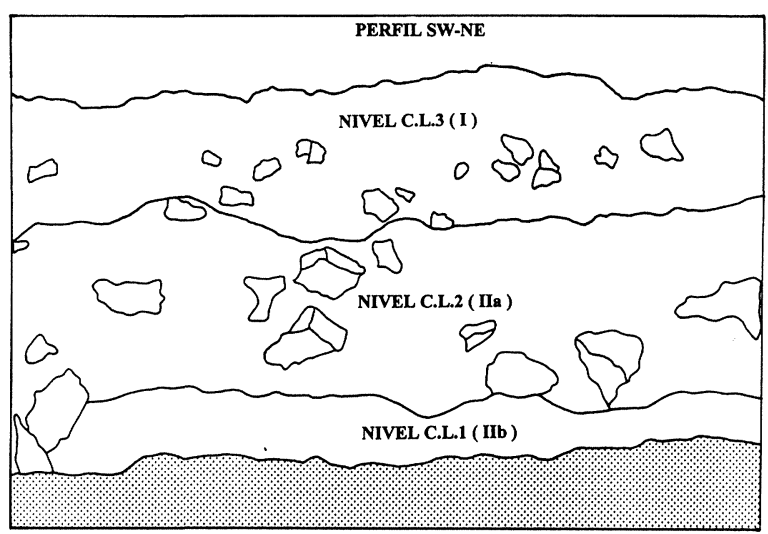

Fig. 4. Corte estratigráfico del sondeo, con indicación de los niveles litoestratigráficos y arqueológicos. 
lógico IIb y es estéril tanto paleontológica como arqueológicamente.

- Nivel C.L.2: Arenas de color gris-amarillento con clastos de areniscas, de $20 \mathrm{~cm}$. de espesor, que descansan en aparente continuidad sobre el nivel infrayacente. Las arenas se mantienen en proporciones similares al nivel anterior $(74,76 \%)$, experimentando una ligera disminución, al igual que los limos $(12,9 \%)$ y arcillas $(1,43 \%)$, mientras que los cantos y gravas sufren un considerable aumento $(10,89 \%)$.Al igual que en el nivel 1 , predominan las arenas finas a las que siguen las de grano medio. Entre los materiales gruesos aparecen representados gravas y cantos de areniscas, tanto angulosos como ligeramente redondeados, con formas prismáticas e incluso con tendencia planar (pequeñas lajas o plaquetas). Las arenas son de cuarzo al igual que la fracción fina, que registra la presencia como accesorios de los feldespatos, además de caolín y micas. Su geometría es tabular y su disposición interna masiva, con un cierto predominio de los cantos y las gravas hacia el techo. Se corresponde con el nivel arqueológico IIa y en él han aparecido de manera desordenada abundantes materiales líticos de clara adscripción superopaleolítica, no habiéndose documentado en el transcurso de la excavación ningún resto orgánico (carbones, huesos ...).

- Nivel C.L.3: Materiales que constituyen un revuelto superficial formado por arenas y clastos de areniscas, afectados por bioturbación de origen vegetal.Alcanza una potencia máxima de $14 \mathrm{~cm}$. Corresponde al nivel I de la estratigrafía arqueológica.

Además, en las paredes del abrigo II observamos marcas de sedimento a una altura sobre el suelo actual que varía entre 100 y $60 \mathrm{~cm}$. y que indican la existencia en la cavidad de un antiguo relleno que al menos alcanzó esta cota en su interior, relleno que fue desmantelado (4).

En el diagrama acumulativo adjunto (Fig. 5) reflejamos gráficamente de forma secuencial las características texturales (granulometría global) de los niveles C.L.1 y C.L.2; la tabla 1 contiene los resultados de los análisis mineralógicos de la fracción fina obtenidos por difracción de rayos X (DRX). Hemos omitido los datos analíticos del nivel C.L.3 o superficial por carecer de interés al ser el producto de la removilización de los sedimentos del nivel C.L.2.

(4) Estas marcas de sedimento recubren una de las figuras grabadas en las paredes de los abrigos (un triángulo equilátero), lo cual implica una datación indirecta (Mas Cornellà et alii, 1995).

T. P., 55, n. ${ }^{\circ} 2,1998$

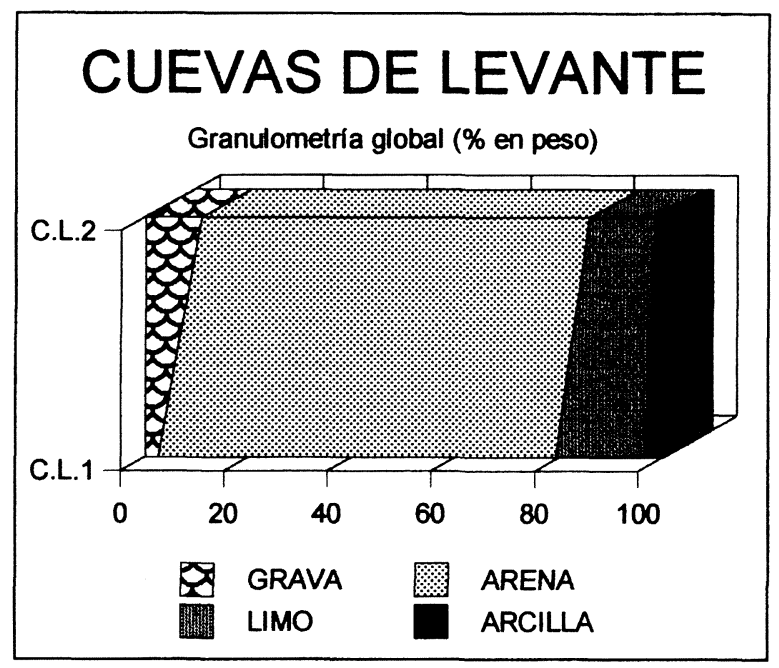

Fig. 5. Diagrama acumulativo de la granulometría global de los niveles del sondeo de las Cuevas de Levante.

\begin{tabular}{|c|c|c|c|}
\hline MUESTRAS & $\begin{array}{c}\text { MINERALES } \\
\text { PRINCIPALES }\end{array}$ & $\begin{array}{c}\text { MINERALES } \\
\text { SECUNDARIOS }\end{array}$ & $\begin{array}{c}\text { ACCESORIOS Y } \\
\text { TRAZAS }\end{array}$ \\
\hline C.L.2 & CUARZO & CAOLIN & MICA, FELDESPATO \\
\hline C.L.1 & CUARZO & CAOLIN & MICA, ESMECTITA \\
\hline
\end{tabular}

Tab. 1. Mineralogía de la fracción fina (DRX) de los niveles del sondeo de las Cuevas de Levante.

Más explícitas son las curvas granulométricas (obtenidas mediante el programa CURGRA, Hernández Rodero et alii, 1987-88) de las dos muestras analizadas que nos permiten distinguir la existencia de varias poblaciones granulométricas en su composición (Fig. 6) que tienen diferentes signifi-

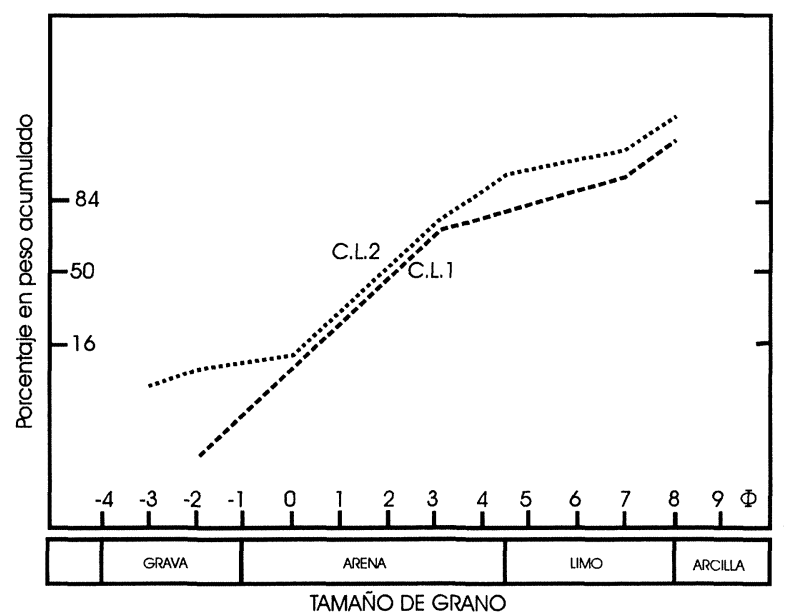

Fig. 6. Curvas granulométricas de los niveles del sondeo de las Cuevas de Levante. 
cados dinámicos. En la curva del nivel C.L.1 apreciamos la presencia de tres tramos correspondientes a diferentes poblaciones: una que comprende las gravas y las arenas hasta el tamaño fino, otra de arenas muy finas y limos hasta su tamaño medio y otra que agrupa a los limos finos y muy finos, y las arcillas. La primera de estas poblaciones corresponde a una carga transportada por rodadura, mientras que las dos últimas podrían asimilarse a depósitos de acreción vertical, interviniendo la decantación y la infiltración gravitacional. La curva del nivel C.L. 2 nos ofrece una mayor mezcla de poblaciones granulométricas: una que corresponde a los tamaños gruesos (cantos, gravas y arenas muy gruesas), otra con el resto de las arenas, una tercera de limos hasta su tamaño medio y una cuarta de limos finos y muy finos, y arcillas. En este nivel, las dos primeras poblaciones responden a un régimen de arrastre por rodadura con variaciones energéticas, mientras que las dos últimas, al igual que en caso anterior, tienen su origen en procesos de acreción vertical.

En cuanto a los parámetros estadísticos (Tab. 2) observamos que el tamaño medio de los sedimentos (media) se sitúa en torno al tamaño arena fina, al igual que el tamaño más frecuente (mediana), existiendo una asimetría positiva en el nivel C.L.1, desviándose la media hacia tamaños inferiores a los de la mediana, mientras que en el nivel C.L.2 esta asimetría es ligeramente negativa, con una desviación de la media hacia tamaños ligeramente superiores a los de la mediana. La clasificación pasa de ser mala en el nivel C.L.1 a regular en el C.L.2. Por tanto, la energía cinética media del transporte sería moderada a baja, con ligeros aumentos en el nivel C.L.2, siendo en general el poder clasificador del agente de transporte bajo, si bien la existencia de una mejor clasificación de los sedimentos en el nivel C.L.2 puede venir condicionada por la naturaleza de las areniscas de las que proceden estas arenas. En el nivel C.L.1 la asimetría positiva y la mayor presencia de materiales finos nos indica la infiltración en profundidad de finos procedentes de los niveles superiores.

\begin{tabular}{|c|c|c|c|c|}
\hline MUESTRAS & MEDIANA & MEDIA & CLASIFICACIÓN & ASIMETRÍA \\
\hline C.L. 2 & 2,10750 & 2,09876 & 1,69091 & $-5,16864$ E-03 \\
\hline C.L.1 & 2,26498 & 2,86861 & 2,27526 & 0,264305 \\
\hline
\end{tabular}

Tab. 2. Parámetros estadísticos que definen las curvas granulométricas de los niveles del sondeo de las Cuevas de Levante.

\subsection{Interpretación}

El aspecto de campo de los niveles, su disposición geométrica y espacial, y los análisis sedimentológicos realizados nos permiten afirmar que la génesis de estos depósitos responde a una sedimentación por flujos laminares de baja energía del tipo de la arroyada difusa producida por aguas de escorrentía superficial que toman los sedimentos disgregados de las areniscas que componen el suelo del abrigo, sus paredes y el resalte rocoso, y los arrastran siguiendo la línea de máxima pendiente de la ladera situada a los pies del abrigo. Hacia el techo de la secuencia se observan momentos de mayor energía en los que las aguas de escorrentía son capaces de arrastrar pequeños clastos autóctonos procedentes del retroceso de la visera y del desmantelamiento del resalte rocoso.

A la vista de lo anterior, los depósitos estudiados corresponden a una deposición secundaria de unos materiales que se encontraban en el interior del abrigo y que fueron desmantelados y arrastrados por arroyada difusa unos metros más abajo. Los abundantes restos líticos superopaleolíticos que aparecen de forma desordenada en el nivel C.L.2 se encontrarían, por tanto, en posición secundaria. Estos materiales aparecen no sólo en la cata realizada sino también en un radio de unos $50 \mathrm{~m}$. pendiente abajo. Además, como hemos señalado, se observan procesos postsedimentarios, como la infiltración gravitacional de materiales finos desde la superficie hacia los niveles inferiores, materiales que proceden también de la desintegración de la roca donde se desarrolla el abrigo (matriz de areniscas). Actualmente se observa circulación de aguas en las entalladuras que limitan el abrigo, circulación que se sigue traduciendo en flujos laminares superficiales que discurren por la pendiente.

Litoestratigráficamente podemos considerar una única unidad dividida en tres subunidades que se asimilarían a los tres niveles descritos, cuya correlación con los niveles arqueológicos y su posición cronoestratigráfica aproximada mostramos en la tabla 3. La secuencia de procesos que se desprende del análisis de la estratigrafía que ofrece el sondeo realizado en las Cuevas de Levante podemos articularla en las siguientes fases:

- Fase 1. Génesis de la cavidad en algún momento indeterminado del Pleistoceno, en cualquier caso anterior a los últimos estadios del Pleistoceno Superior. 


\begin{tabular}{|c|c|c|c|c|}
\hline $\begin{array}{c}\text { Niveles } \\
\text { litoestratigráficos }\end{array}$ & $\begin{array}{c}\text { Niveles } \\
\text { arqueologicos }\end{array}$ & Procesos & $\begin{array}{c}\text { Contenido } \\
\text { arqueológico }\end{array}$ & Cronoestratigrafia \\
\hline C.L.3 & $\begin{array}{c}\text { I } \\
\text { (= superficial) }\end{array}$ & $\begin{array}{c}\text { Bioturbación } \\
\text { Infiltración }\end{array}$ & Revuelto & Holoceno - Actual \\
\hline C.L.2 & Ila & Arroyada difusa & $\begin{array}{c}\text { Solutrense Superior } \\
\text { Evolucionado }\end{array}$ & $\begin{array}{c}\text { Pleistoceno superior } \\
\text { final }\end{array}$ \\
\hline C.L.1 & Ilb & $\begin{array}{c}\text { Arroyada difusa } \\
\text { de baja energia }\end{array}$ & Estéril & Pleistoceno superior \\
\hline
\end{tabular}

Tab. 3. Correlación entre los niveles litoestratigráficos y arqueológicos del sondeo de las Cuevas de Levante, indicando los procesos geológicos, el contenido arqueológico y su posición cronoestratigráfica estimada.

- Fase 2. Ocupación del abrigo por grupos humanos del Paleolítico Superior disponiéndose los restos tecnoculturales sobre sedimentos producto de la alteración de las areniscas que constituyen el abrigo. La industria recuperada corresponde al Solutrense Superior Evolucionado. Este dato sitúa la fase de ocupación humana y del relleno del abrigo con materiales antrópicos hacia los últimos estadios del Pleistoceno Superior.

- Fase 3. Desarrollo de procesos de arroyada difusa de muy baja energía responsables de la génesis del nivel C.L.1. Estos arrastres afectarían a los materiales superficiales del relleno del abrigo y su baja energía únicamente les permitiría arrastrar materiales finos.

- Fase 4. Desmantelamiento del depósito que rellenaba parcialmente el abrigo y distribución por la pendiente de los materiales arqueológicos actuando como mecanismo de transporte la arroyada difusa, con una energía superior a la de la fase 3, dando lugar a los depósitos del nivel C.L.2. Estos procesos se situarían probablemente en el tránsito Pleistoceno Superior - Holoceno, en un momento de cierta pluviosidad detectada en otros yacimientos andaluces (Jordá Pardo et alii, 1990).

- Fase 5. Infiltración gravitacional de sedimentos finos en los niveles más profundos (nivel C.L.1), removilización del tramo superior de los depósitos resedimentados en la fase 3 por procesos de bioturbación (nivel C.L.3) y desarrollo de actividades antrópicas superficiales (uso de los abrigos como majadas, roturaciones ...) durante el Holoceno y hasta la actualidad.

La disposición actual de los niveles que componen el depósito situado delante de las Cuevas de Levante responde a procesos de origen natural y cultural ( $N$-transforms y $C$-transforms: Schiffer, 1987), existiendo procesos tanto de formación como procesos de transformación o postdeposicionales, siendo estos últimos claramente predominantes sobre los primeros. El origen y el carácter de los procesos que se observan en las diferentes fases y las relaciones entre todos ellos, que aparecen plasmadas en el registro arqueológico de las Cuevas de Levante se sintetizan en la tabla 4.

\begin{tabular}{|c|c|c|c|}
\hline FASE 5 & FASE 5 & \multirow{3}{*}{$\begin{array}{l}\text { PROCESOS DE } \\
\text { TRANSFORMACIÓN }\end{array}$} & \multirow{5}{*}{$\begin{array}{l}\text { CARÁCTER DE } \\
\text { LOS PROCESOS }\end{array}$} \\
\hline & FASE 4 & & \\
\hline & FASE 3 & & \\
\hline \multirow[t]{2}{*}{ FASE 2} & FASE 2 & \multirow{2}{*}{ PROCESOS DE FORMACIÓN } & \\
\hline & FASE 1 & & \\
\hline CULTURAL & NATURAL & & \\
\hline \multicolumn{2}{|c|}{$\begin{array}{l}\text { ORIGEN DE LOS } \\
\text { PROCESOS }\end{array}$} & & \\
\hline
\end{tabular}

Tab. 4. Relaciones entre las fases y la naturaleza de los procesos que han intervenido en la génesis y transformación del registro arqueológico de las Cuevas de Levante.

\section{LA INDUSTRIA LÍTICA}

El paquete estratigráfico consta de dos unidades arqueológicas claramente diferenciadas, subdividiéndose la unidad inferior en dos niveles (Fig. 4). En primer lugar y de arriba a abajo, observamos un primer nivel superficial revuelto con una potencia máxima de $14 \mathrm{~cm}$. En este nivel aparecieron gran cantidad de materiales, algunos de ellos en posición secundaria. El siguiente estrato, más potente $(20 \mathrm{~cm}$.), es el que contiene los materiales superopaleolíticos, que si bien no están in situ, no han sido desplazados excesivamente. Las piezas aparecen en posición horizonal y se concentran en la parte intermedia de este paquete, inmediatamente por debajo de los bloques que delimitan el nivel I y este nivel IIa.A continuación se encuentra un breve paquete, de apenas $8 \mathrm{~cm}$. de espesor, completamente estéril y que se deposita directamente sobre la roca madre, que hemos definido como nivel IIlb. El sedimento, bastante suelto, está formado por arenas y arcillas arenosas, entre las que aparecen frecuentemente plaquetas de exfoliación de la roca. En la parte superior aparecía muy seco, mientras que en la base estaba muy húmedo.

\subsection{Nivel I}

En el nivel I (C.L.3) se hallaron un total de 455 restos líticos de los que $443(97,36 \%)$ componen el resto de talla y $12(2,63 \%)$ representan el material retocado. No se encontró ningún resto óseo ni tampoco carbones o cenizas. Este hecho puede deberse a la acidez del sedimento. También apa-

T. P., 55, n. $^{\circ} 2,1998$ 
recieron 66 fragmentos cerámicos de diferentes épocas, 7 fragmentos de ocre naranja y 2 pequeñas plaquetas de arenisca.

Dentro del resto de talla, podemos observar que el 97,14\% de las piezas están realizadas sobre sílex, mientras que tan sólo el 2,85\% lo está sobre arenisca. En cuanto a los útiles retocados, todos ellos están tallados sobre sílex. El porcentaje de piezas con cortex es muy bajo, lo que significa o bien un descortezado preliminar en las fuentes de materia prima o bien la utilización de sílex tabular, con una menor superficie cortical.

En cuanto al soporte, podemos ver que en el resto de talla predominan las lascas y lasquitas $(48,98 \%)$ frente a las hojas y hojitas $(12,86 \%)$, mientras que en los útiles esta proporción es idéntica para los dos grupos $(41,66 \%)$. Hemos clasificado otros tipos de soporte pero los porcentajes son menos significativos. Señalaremos sin embargo el tanto por ciento de los debris $(10,60 \%)$ y el de los núcleos $(1,80 \%)$, siendo la mayoría prismáticos con un plano de percusión.

En este primer nivel, como ya hemos anticipado, la cantidad de piezas retocadas es bastante escasa, posiblemente debido a que faltan las piezas de la superficie, recogidas durante la prospección del año 1990 y que no hemos considerado oportuno unir a esta serie industrial. El análisis tipológico muestra la existencia de un número muy reducido de tipos (Tab. 5). Fuera de la lista tipológica adoptada, hemos identificado 2 hojas retocadas $(16,66 \%)$ y 3 lascas retocadas $(25 \%)$. El retoque que se aprecia en la mayoría de los casos es simple directo y bastante marginal.

\begin{tabular}{|c|l|c|}
\hline $\mathbf{N}^{\mathbf{0}}$ & \multicolumn{1}{|c|}{ Tipos } & Porcentaje \\
\hline 1 & Buril diedro de ángulo sobre truncatura retocada & $8,33 \%$ \\
1 & Hojita de dorso simple & $8,33 \%$ \\
1 & Truncatura recta & $8,33 \%$ \\
4 & Muescas retocadas & $33,33 \%$ \\
\hline
\end{tabular}

Tab. 5. Lista tipológica del nivel I.

\subsection{Nivel IIa}

El número de restos hallados en el nivel IIa (C.L.2) es de 859 de los que 771 (89,75\%) componen el resto de talla y $63(7,33 \%)$ los útiles retocados (Fig. 7 y 8). La materia prima utilizada se distribuye de la siguente forma: 834 piezas de sílex $(97,08 \%)$ y 25 de arenisca $(2,91 \%)$. Al igual que en el nivel anterior, la presencia de cortex es mínima.
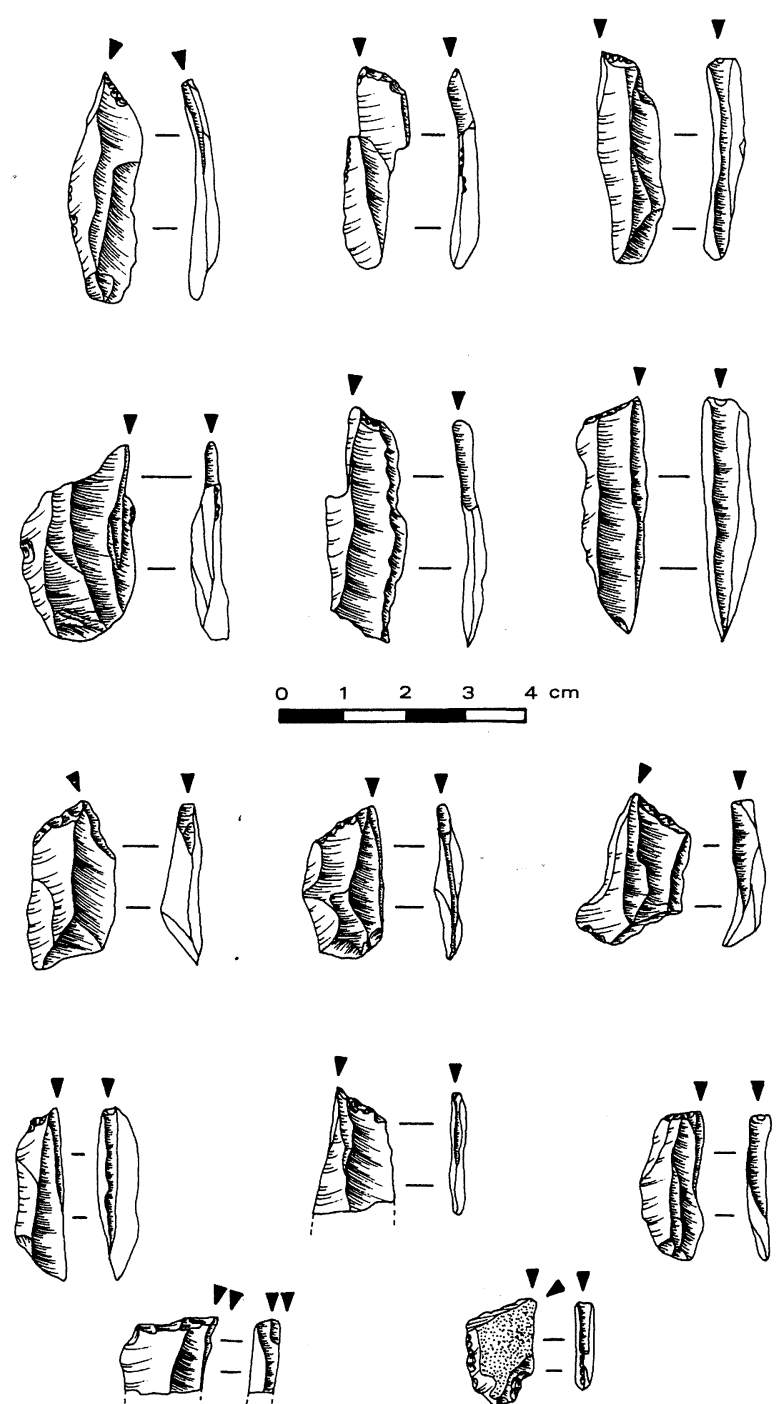

Fig. 7. Piezas retocadas del nivel IIa: buriles.

En cuanto al soporte observamos una gran desigualdad con el estrato superior, fundamentalmente en la diferencia porcentual entre tipos. En el resto de talla predominan sin embargo las lascas y lasquitas $(28,66 \%)$ frente a las hojas y hojitas que alcanzan un $20,10 \%$. Se aprecia también un alto número de fragmentos no identificables $(28,53 \%)$ y de debris $(12,32 \%)$. El resto de los soportes clasificados poseen porcentajes menores.

El soporte de los útiles retocados varía sustancialmente con respecto al nivel I ya que observamos un aumento muy significativo $(57,40 \%)$ de las piezas talladas sobre hojas u hojitas, mientras que las lascas presentan un porcentaje del $33,33 \%$, netamente inferior. 

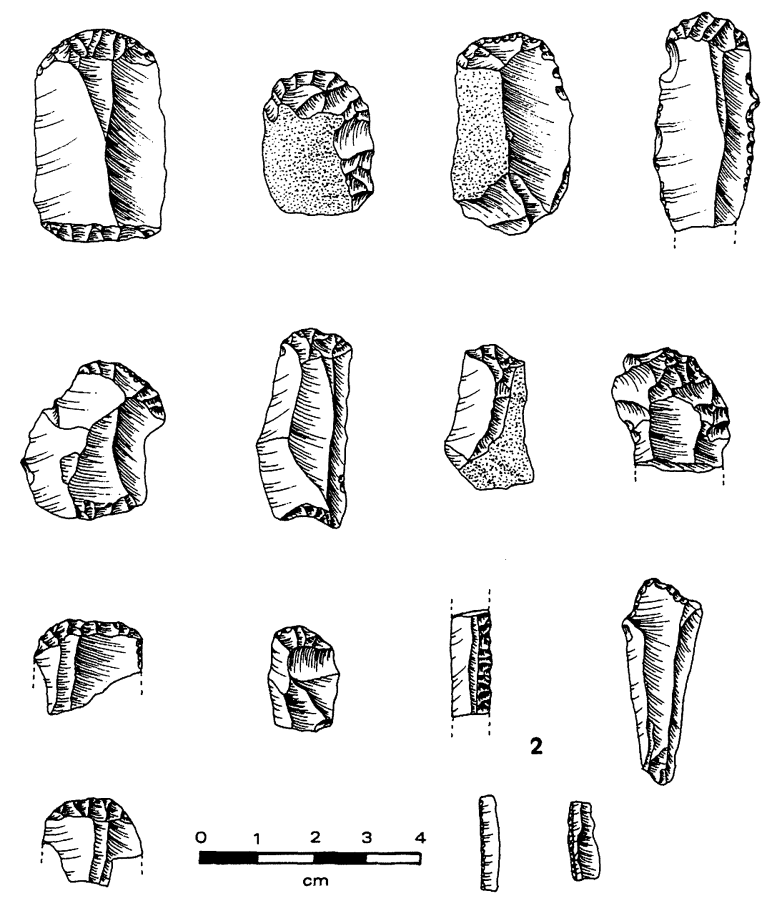

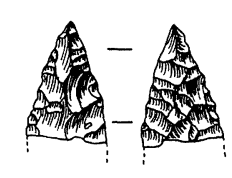

4

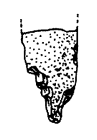

5

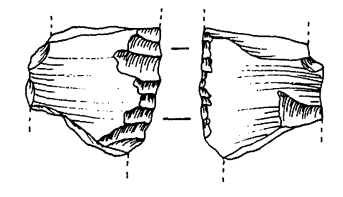

6
Fig. 8. Piezas retocadas del nivel Ila: raspadores (1), hojitas de dorso (2), truncatura (3), punta de aletas y pedúnculo (4), punta de muesca (5) y pieza solutrense bifacial (6).

La lista tipológica que hemos establecido para el nivel IIa, se distribuye según los tipos de la tabla 6. Además y fuera de la lista tipológica propiamente dicha, hemos clasificado 5 hojas retocadas $(9,25 \%)$ y 3 lascas retocadas $(5,55 \%)$.

\subsection{Interpretación}

La serie industrial analizada nos muestra que el índice de raspadores alcanza un porcentaje del I.R. $=25,93 \%$, mientras que el de los buriles lo supera ampliamente (I.B. $=46,30 \%)$. En cuanto a los índices restringidos el de los buriles diedros de ángulo (I.B.d.(r) $=46,30 \%$ ) y el de los buriles sobre truncatura (I.B.t. $(r)=35,19 \%)$, vemos que son relativamente similares.

El índice de los útiles realizados sobre hojitas

\begin{tabular}{|c|l|r|}
\hline $\mathbf{N}^{\mathbf{0}}$ & \multicolumn{1}{|c|}{ Tipos } & Porcentaje \\
\hline 2 & Raspador sobre hoja retocada & $3,70 \%$ \\
1 & Raspador en extremo de hoja & $1,85 \%$ \\
2 & Raspador doble & $3,70 \%$ \\
5 & Raspador sobre lasca & $9,25 \%$ \\
4 & Fragmento de raspador & $7,40 \%$ \\
19 & Buril diedro de ángulo sobre truncatura retocada & $35,18 \%$ \\
6 & Buril diedro de ángulo & $11,11 \%$ \\
1 & Fragmento de punta de muesca & $1,85 \%$ \\
1 & Fragmento de punta de aletas y pedúnculo & $1,85 \%$ \\
1 & Pieza solutrense bifacial & $1,85 \%$ \\
1 & Denticulado & $1,85 \%$ \\
2 & Perforador & $3,70 \%$ \\
3 & Truncatura & $5,55 \%$ \\
2 & Hojita de dorso simple & $3,70 \%$ \\
3 & Hojita de fino retoque directo & $5,55 \%$ \\
2 & Muescas retocadas & $3,70 \%$ \\
\hline Total: 54 & & $100 \%$ \\
\hline
\end{tabular}

Tab. 6. Lista tipológica del nivel IIa.

únicamente representa un $9,26 \%$ (I.h.). Sin embargo el grupo de útiles que de alguna forma puede caracterizar este conjunto industrial es el solutrense, que aunque posee un bajo porcentaje (I.G.S. $=5,56 \%$ ), junto con el grupo de los buriles y el de las hojitas, nos permite encuadrar este nivel en un horizonte cultural del Solutrense Superior Evolucionado.

Como ya hemos propuesto en otras publicaciones (Ripoll López, 1988, 1989, 1991, e.p.), un encuadre tan concreto únicamente se puede efectuar cuando se posee una serie industrial suficientemente ámplia, y éste no es el caso, ya que se trata de un reducido sondeo estratigráfico provisional. Pero creemos poder adelantar que, dada la existencia de una punta de aletas y pedúnculo, de una punta de muesca y de una pieza solutrense bifacial -a pesar de que todas ellas aparecen fracturadas-, su encuadre cultural Solutrense es acertado.

Por otra parte, la existencia de un índice tan alto de buriles, junto con las escasas hojitas, nos podría hacer pensar que se trata de un nivel Magdaleniense, pero la presencia de las piezas antes mencionadas nos ratifica en el encuadre cultural propuesto. Como ya hemos expuesto con anterioridad (Ripoll López, 1988, 1989, 1991, e.p.), creemos que en la zona andaluza -donde la existencia del Magdaleniense Inicial y Medio no está atestiguada- estos estadios culturales se verían sustituídos por el Solutrense Superior Evolucionado.

\section{CONSIDERACIONES FINALES}

El yacimiento de las Cuevas de Levante posee un gran interés, que sin duda se verá completado y confirmado en futuras actuaciones sistemáticas, cuya realización plantearemos y solicitaremos a medio 
o largo plazo en el marco que establece la Ley 1/ 1991, 3 de julio, de Patrimonio Histórico de Andalucía, y Decreto 32/1993, 16 de marzo, por el que se aprobó el Reglamento deActividades Arqueológicas en la Comunidad Autónoma de Andalucía.

La urgencia que condujo a esta actuación ha demostrado que el yacimiento de las Cuevas de Levante no corre el peligro que la motivó, y no creemos oportuno acometer una intervención inmediata. Sin embargo sí consideramos necesario hacer un seguimiento más o menos periódico con el fin de comprobar posibles alteraciones que podrían revestir cierta gravedad.

\section{BIBLIOGRAFÍA}

BreuIL, H. y BurkitT, M.C. (1929): Rock paintings of southern Andalusia. A description of a Neolithic and Copper Age art group. Clarendon Press. Oxford.

Fontвoté, J.M. (1983): "La Cordillera Bética. Zonas internas y unidades adyacentes". Libro Jubilar J.M. Rios. Geología de España. IGME. Madrid: 251-343.

Fontboté, J.M. y Vera, J.A. (1983): "La Cordillera Bética. Introducción”. Libro Jubilar J.M. Rios. Geología de España. IGME. Madrid: 205-218.

Gavala, J. (1916): "Regiones petrolíferas de Andalucía". Boletín del Instituto Geológico Minero de España, 37: 33-208.

- (1929): "La geología del Estrecho de Gibraltar". Boletín del Instituto Geológico Minero de España, 51: 3-36.

Hernández Rodero, M.F.; Chicharro, P.M. y Benito, R. (1987-88): "Representación de curvas granulométricas por ordenador". El Geólogo, 26-27: 53-55.

Jordá Pardo, J.F.; Aura Tortosa, J.E. y Jordá Cerdá, F. (1990): "El límite Pleistoceno-Holoceno en el yacimiento de la Cueva de Nerja (Málaga)". Geogaceta, 8 : 102-104.

LEROI-Gourhan, A. (1952): Les fouilles préhistoriques (Téchniques et méthodes). Editorial Picard. París.

Mas Cornellà, M. (1986-87): "Los grabados de la Cueva del Arco (Conjunto rupestre del Tajo de las Figuras) y del Abrigo del Tajo de Albarianes (Medina Sidonia, Cádiz)". Ars Praehistorica, V/VI: 247-252.

- (1988): "El conjunto rupestre delTajo de las Figuras. Estado actual de las investigaciones en Sierra Momia (Cádiz)”. En E. Ripoll Perelló (ed.): Actas del Congreso Internacional El Estrecho de Gibraltar (Ceuta, 1987). I: Prehistoria e Historia de la Antigüedad. UNED. Madrid: 293-303.

- (1993): "El arte prehistórico en las sierras del Campo de Gibraltar. Proyecto: Las manifestaciones rupestres prehistóricas de la zona gaditana”. En J.M. Campos Carrasco y F. Nocete Calvo (eds.): Investigaciones arqueológicas en Andalucía, 1985-1992, Proyectos. Junta de Andalucía. Huelva: 263-271.
Mas Cornellà, M.; JoRdá Pardo, J.F.; Cambra Sánchez, J.; Mas Riera, J. y Lombarte Carrera, A. (1994): "La conservación del arte rupestre en las sierras del Campo de Gibraltar. Un primer diagnóstico". Espacio, Tiempo y Forma. Serie I, 7: 93-128.

Mas CoRnellà, M. y Ripoll López, S. (1996): "El Paleolítico Superior en el Sur de Cádiz”. Espacio, Tiempo y Forma. Serie I, 9: 269-273.

Mas Cornellà, M.; Ripoll López, S.; Martos Romero, J.A.; Paniagua Pérez, J.P.; López Moreno de RedroJO, J.R. y BERGMANN, L. (1995): “Estudio preliminar de los grabados rupestres de la Cueva del Moro (Tarifa, Cádiz) y el arte paleolítico del Campo de Gibraltar". Trabajos de Prehistoria, 52 (2): 61-81.

Mas Cornellà, M.; Ripoll López, S.; Torra Colell, G.; Jordá Pardo, J.F.; Gavilán Ceballos, B. y Vera RoDRÍGUEZ, J.C. (1996): “El poblamiento prehistórico del Campo de Gibraltar". Espacio, Tiempo y Forma. Serie I, 9: 207-223.

Mas Cornellà, M. y SANCHIDRIÁn ToRTI, J.L. (1991): "Proyecto de investigación arqueológica 'Las manifestaciones rupestres prehistóricas de la zona gaditana'. 1990: Prospección arqueológica superficial en las Cuevas de Levante y el Conjunto rupestre del Tajo de las Figuras (Sierra Momia)".Anuario Arqueológico de Andalucía, 1990. II. Junta de Andalucía. Sevilla: 359-370.

Munsell (1954): Munsell soil color chart. Munsell Color Company. Baltimore.

Ripoll López, S. (1988): La Cueva de Ambrosio (VélezBlanco, Almería) y su posición cronoestratigráfica en el Mediterráneo Occidental. British Archaeological Report, 462. Oxford.

- (1989): "Le gisement de La Cueva de Ambrosio: Nouveaux apports au Solutréen de la Péninsule Ibérique". L'Anthropologie, 92: 851-886.

- (1991): "Le solutréen dans le Sud de la Péninsule Ibérique". Colloque International sur les industries à pointes foliacées du Paléolithique supérieur européen. Organizado por el InstytutArcheologii Universytet Jagiellonski, Cracovia (Polonia, 1989). Les feuilles de pierre, ERAUL, 42. Liège: 449-465.

- (ep.): "Die stratigraphisch-zeitliche Einordnung der Cueva de Ambrosio in Almería, (Südspanien)". UISPP. Mainz 1987.

Ripoll López, S.; Mas Cornellà, M. y Perdigones MoreNO, L. (1993): "Actuaciones de urgencia en las Cuevas de Levante y Cubeta de la Paja (Sierra Momia, Benalup, Cádiz)". Anuario Arqueológico de Andalucía, 1991. II. Junta de Andalucía. Sevilla: 105-110.

Ripoll López, S.; Mas Cornellà, M. y Torra Colell, G. (1991): "Grabados paleolíticos en la Cueva del Tajo de las Figuras (Benalup, Cádiz)". Espacio, Tiempo y For$m a$. Serie I, 4: 111-126.

SCHIFFer, M.B. (1987): Formation Processes of Archaeological Record. University of New Mexico Press. Alburquerque. 